\title{
Information Management for Travelers: Towards Better Route and Leisure Suggestion
}

\author{
Evgeny Pyshkin \\ Software Engineering Lab. \\ University of Aizu \\ Aizu-Wakamatsu, 965-8580, Japan \\ Email: pyshkin@icc.spbstu.ru
}

\author{
Alexander Baratynskiy, Alexander Chisler, Boris Skripal \\ Institute of Computer Science and Technology \\ Peter the Great St. Petersburg Polytechnic University \\ St. Petersburg, 195251, Russia \\ Emails: \{baratynskiy, alexander.chisler, skipalboris\}@gmail.com
}

\begin{abstract}
Contemporary travel information services are connected to huge amount of travel related data used for improving personalized suggestions. Such suggestions include finding better routes, access to amusement and educational amenities implemented as digital services, as well as the features for people collaboration, and for planning leisure time with respect to existing attractiveness evaluation algorithms under time-budget constraints. Much effort is required for supporting personalized itineraries construction in such a way which would leverage existing cultural and technological user experience. In this paper we analyze the underlying algorithms and major components being an implementation of the proposed model investigated with particular attention to annotated leisure walk route construction, traveler collaboration and travel meeting management. In sum, we make an effort to address a number of complex issues in the area of developing models, interfaces and algorithms required by modern travel services considered as an essential application of a human-centric computing multidisciplinary paradigm.
\end{abstract}

\section{INTRODUCTION}

There is no exaggeration in saying that traveling is one of remarkable ways to discover the world. Among different obvious factors (which include journey time planning, accommodation management, equipment preparation, etc.) there are many aspects related to the careful forethought of a journey which would make it coming up well to the traveler's interests and expectations. To a significant extent, present day information services for travelers are about personalization, extending usage scenarios, improving suggestions and recommending journey options on the base of the information retrieved from various warehouses containing huge amount of travel related data.

The idea of our approach is to combine user experience orientation and rich facilities of the present day information retrieval, processing and presentation tools for the benefits of better travel planning, itinerary construction and traveler experience sharing. Indeed, with current level of computer-assisted tools and methods tourists expect more facilities than simply finding a fastest and cheapest way or getting a direction. They expect to be advised how to deal with many competitive factors of route construction, some of them (like sight attractiveness) aren't easily formalizable. The problems of developing better personalized services for travelers are within the scope of the emerging domain of urban computing [1], [2] where suggestion environments are rapidly developing. Thus, leisure could be suggested: we believe that advancing services for travelers is a perfect area to be upgraded by introducing better suggestion facilities

In this work we don't pretend to cover all possible suggestion use cases supported by a big variety of existing applications. We partially address only a selection of scenarios representing five major aspects of travel planning and management:

1) Journey preparation and planning;

2) Itinerary construction automation and navigation;

3) Multimedia assistance automation;

4) Traveler interaction and collaboration;

5) Post-travel experience.

The listed aspects (which are not exhaustive, nor totally independent) and the corresponding scenarios are described in Section II.

\section{Aspects And Use CASES}

Let us examine our selection of travel planning and management aspects.

The first aspect is journey preparation and planning Nowadays travelers still use but aren't totally satisfied with traditional paperback editions of numerous travel guides containing plenty of maps and city plan fragments. Voyagers consult different guides implemented as software applications (currently available on many mobile platforms and advertised on the web sites like Musement ${ }^{1}$, Izi.travel ${ }^{2}$ or PocketGuide ${ }^{3}$ ), they share their experience via social networks and traveler forums available on relevant web sites (like TripAdvisor ${ }^{4}$ ). Many applications exist for mobile devices supporting GPSsensors, electronic maps, as well as various multimedia features. In Section III-A we provide a brief survey of existing web resources for travelers.

Instead of taking predefined packages, many people prepare their own itineraries with the help of information available on the web sites for travelers. Thus, the second aspect is route construction automation and navigation. While planning

\footnotetext{
${ }^{1}$ www.musement.com/

${ }^{2}$ https://izi.travel/en

${ }^{3}$ http://pocketguideapp.com

${ }^{4} \mathrm{http} / / /$ tripadvisor.com
} 
visiting some area for a certain period of time, tourists are unlikely able to visit each attraction. Effectively, they solve a kind of fuzzy optimization problem in order to select something that would be specifically interesting to them. Tourists select points of interest (POIs) depending on their significance from a certain point of view. Hence, one of possible application of traveler advisory systems is to navigate the selection process by implementing the criteria representing a tourist object attractiveness by some formal schema. In Section III-B we analyze possible approaches for such a formalization.

Creating personalized itineraries requires using rich facilities of multimedia assistance automation. This aspect is connected to different issues, including assisting visually impaired pedestrians [3], creating multimedia travel books integrated with electronic maps and accessible from mobile devices [4], creating audio guides for museums and cultural sights [5], [6], designing personalized recommendation systems in order to mitigate information overload [7], and so on.

The next aspect is traveler interaction and collaboration. Somehow, many current efforts are about delivering personalized solutions allowing travelers to leverage and to share their experience and/or to follow major scenarios we could learn as a result of travelers' experience study [8], [9].

Personalization and user collaboration is connected strongly to the possibility to leverage post-travel experience knowledge. Among existing solutions for travel reporting we can cite a couple of examples like TripJournal ${ }^{5}$ and TripCast ${ }^{6}$.

To sum up, we agree with the statement from [10] that the focus of many existing solutions is on creating a technology which wouldn't support only a kind of time-budget optimization problem but would allow travelers to develop their own memorable experience (the latter term being borrowed from [11]).

\section{STATE-OF-THE-ART APPROACHES}

This section contains a brief survey of state-of-the art approaches developed and used in the domain of traveling related information systems.

\section{A. General Information Services for Travelers}

Apart from research projects (examined in details in further sections), there are two big classes of present day electronic services for tourists: thematic web sites (which are sometimes linked to special software applications) and a huge variety of mobile applications. Among popular web based solutions there are the following major groups:

- Web sites for hotel, flight, restaurant searching and booking: they are kinds of aggregation bridges to many external services; sometimes they contain traveler forums and features for collecting and displaying user feedback and user impressions. Good examples are TripAdvisor and Expedia ${ }^{7}$.

\footnotetext{
${ }^{5}$ www.trip-journal.com/

${ }^{6}$ https://tripcast.co/

${ }^{7}$ http://expedia.com
}

- Travel guides implemented as a collection of stories and suggestions which are sometimes focused not only on sites and attractions but also on interesting events and on sharing personal experience: particular implementations may contain event calendars, transport and place orientation, integration with electronic maps. Good examples are Timeout $^{8}$, I.Know ${ }^{9}$ and Japan Guide ${ }^{10}$.

- Individual trip planning or collaborative planning: journey agenda and route planning (like in Travefy ${ }^{11}$ and Tripomatic $^{12}$ ), transportation planning (like in RouteRank ${ }^{13}$ and Hyperdia ${ }^{14}$ ).

- Journey and transport trackers, including flight trackers (FlightTrack ${ }^{15}$, GateGuru ${ }^{16}$ ).

- Personalized itineraries construction examined in the subsequent sections of this paper.

- Platforms for sharing user in-travel and post-travel experience: good example is (TravelDiaries ${ }^{17}$ ). Travel diaries are often used by other travelers in time of preparation their future trips.

- Multimedia guides: good examples are audio guides used not only in traditional indoor museum environments but also for outdoor journeys $\left(A z b o^{18}\right.$, Izi.Travel ${ }^{19}$, PocketGuide $^{20}$ ).

- Unusual models: good example is Explorra ${ }^{21}$, an approach where a collection of attractions is accessed after a user selects a color.

Of course, the above mentioned groups exist rarely in its pure form, many features being shared among different solutions. Currently the focus is being shifted to lightweight (mobile) applications targeting the everyday life stories.

\section{B. Itinerary Construction: Interfaces and Implementations}

Among existing solutions for travel itinerary construction we have to mention several projects which are within the scope of our research.

The mobile application TAIS for guiding tourist activity described in [12] is focused on step-by-step itinerary construction in response to user actions and movements. There is an interesting feature of collecting user impressions about the visited POIs. The application generates recommendations collected on the base of other travelers' experience and evaluations. For each POI its detailed information includes a list of images associated with the attraction and its description. As

\footnotetext{
${ }^{8}$ http://www.timeout.com/

${ }^{9}$ http://iknow.travel/

${ }^{10} \mathrm{http} / / / \mathrm{www}$.japan-guide.com

${ }^{11} \mathrm{http}: / / \mathrm{www}$. travefy.com

${ }^{12} \mathrm{http}: / /$ www.tripomatic.com

${ }^{13} \mathrm{http}: / /$ www.routerank.com/en/

${ }^{14} \mathrm{http}: / /$ www.hyperdia.com/

${ }^{15}$ https://www.mobiata.com/apps/flighttrack

${ }^{16}$ www.gateguru.com/

${ }^{17}$ www.traveldiariesapp.com/

${ }^{18} \mathrm{https}: / /$ azboguide.com/en

${ }^{19}$ https://izi.travel/en

${ }^{20} \mathrm{http}: / /$ pocketguideapp.com

${ }^{21}$ https://www.explorra.com/labs/travel-by-color
} 
a routing service the authors use OpenStreetMap API, while Yandex.Schedule API is used for searching available public transportation routes, the latter being a very promising feature.

A tour planning system Aurigo combines a recommendation algorithm with interactive visualization for creating and managing personalized itineraries [10]. To a great extent, this project is in the same direction as the project of ours: the authors investigate a possible balance between an automated and purely manual approaches.

TripBuilder framework described in [13] is an implementation of an approach for planning personalized sightseeing tours in cities. The itineraries are being constructed after analysis of the geo-tagged photos collected from Flickr ${ }^{22}$ and associated with the POIs collected from Wikipedia. The photos are considered as traces revealing the behaviors of tourists and as a source of spatio-temporal information about their sightseeing experience. The itinerary construction is modeled as an instance of the generalized maximum coverage problem with respect to visiting time-budget optimization and to further building of the itinerary as an instance of the traveling salesman problem. The approach was advanced in [14] by applying an algorithm for suggesting contextually relevant POIs on the base of user preferences and interests.

In our previous works (see [15], [16]) we described an approach to design an application which is not limited to obtaining the information about different attractions, it provides the ability of planning and constructing a travel itinerary in advance. That's why tourist guides may use it in their work. We expect that, by using the application, professional experts and amateur guides can prepare their tours both in automatic and manual modes.

In contrast to [17] we couldn't totally agree that "creating an efficient and economic trip plan is the most annoying (our emphasis) job for a backpack traveler". We believe that creating a customized itinerary is a very creative stage which is part automatic, part manual: for producing interesting high quality suggestions the contribution of human experts is extremely important.

Our application focuses a concept of an annotated travel itinerary. which is not a simple path (for instance, the shortest one) between two points on the map, but a route description which includes a set of POIs representing such attractions as architectural sights, museums, historical places, monuments, view points, etc. In order to create a relevant annotation, one should consider including such entities as texts, images (photos, drawing, replicas, diagrams, etc.), multimedia objects (audio or video clips), web links, notes, citations, dates, timeline connections, information about related people, places or events, to cite a few.

Figure 1 gives an idea of existing complexity of a domain specific ontology by an example of architectural points. Figure 2 follows a pattern proposed in [18] and shows major usage scenarios. The common-sense ontology provides a foundation for the information system architecture.

${ }^{22} \mathrm{http}: / /$ www.flickr.com

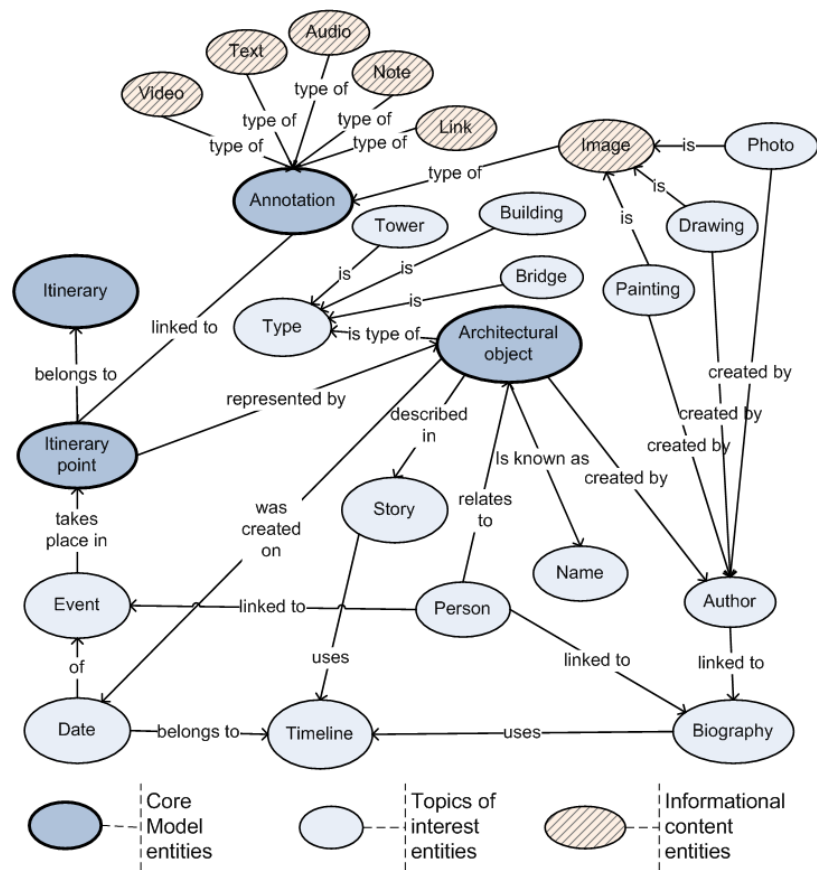

Fig. 1. An example of domain specific ontology fragment

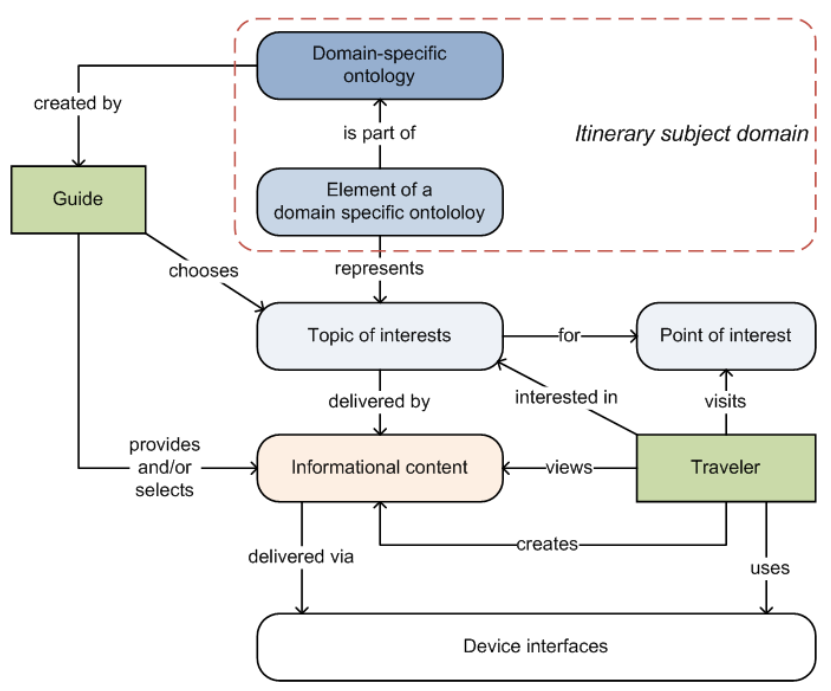

Fig. 2. Common sense ontology

\section{Travel Route Automation: Formal Models and Algorithms}

Itinerary planning automation is still an important aspect even for local itineraries for leisure walks. An obvious formal model representing the problem of generating an itinerary is finding an optimal way on an undirected or directed weighted graph. However the question is not about finding a shortest path. There are many competing factors that have to be taken into consideration:

- POI opening and closing times (time schedule);

- POI visual characteristics (viewpoints); 
- POI purposes and their relation to the journey focus (important for thematically organized itineraries);

- POI importance (in a sense);

- POI types (historical objects, relaxation objects, sanitary facilities, transportation hubs, etc.);

- Dependency on weather, traffic, safety conditions, and similar issues.

Hence, common shortest path algorithms aren't enough. Hereafter we examine possible approaches that could be useful for automatic itinerary construction.

1) Using Genetic Algorithms: An adaptive genetic algorithm described in [19] is based on partitioning the work space by several blocks with unique numbers as Figure 3 shows.

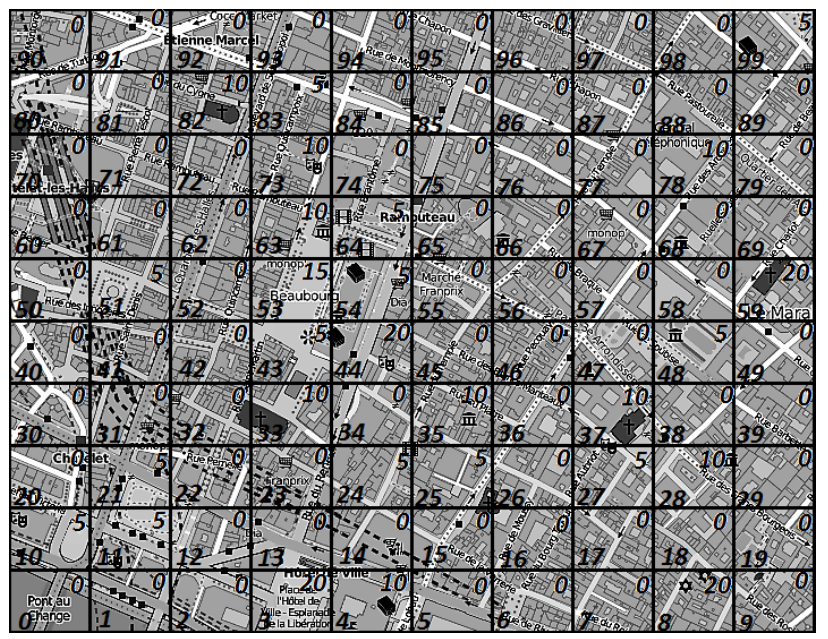

Fig. 3. Division the workspace into blocks

A path is a sequence of "visited" blocks, while a fitness function defined as an adopted version from [19] is as follows:

$$
F=\left(1+\frac{1}{\sqrt{n-1}}\right) \cdot D \cdot C
$$

In equation (1) $n$ is the number of free cells, $D$ is the sum of linear distances between adjacent individuals, $C$ is is the sum of object scores (shown on the upper right corners of each block in Figure 3) within the selected blocks.

This method allows planning routes quickly: on a grid of $10 \times 10$ cells with scale of population equal to 40 and length of each population equal to 20 , a stable population is created after 40-th generation. However the fitting function ignores some important factors, for example, it ignores the walk duration.

2) Random Search Algorithms: In [20] the authors used a greedy randomized adaptive search procedure which could be explained as follows. The first step is to find some start solution (for example, we can select several POIs with the highest popularity and a shortest path between them). The second step is to calculate the value of $F$ function that describes the effect of adding a POI to the route:

$$
F=\frac{T_{\text {beforeAdding }}}{T_{\text {afterAdding }}} \cdot S
$$

In equation (2) $T_{\text {beforeAdding }}$ is a route time before inclusion of current POI, $T_{\text {after Adding }}$ is a time after inclusion of the POI into the best position (i.e. the position corresponding to the time which is as minimal as possible), while $S$ is a score of current object.

The next steps are iterative: the idea is to find several points with the best $F$ value which are not included to the major route, and to select a random point from them, so as to add it into the route. This process is being repeated until we decide to stop. There could be different stop situations: for example, we don't have more time to continue searching, or we don't have any POIs more. Figure 4 gives an illustration for one iteration.

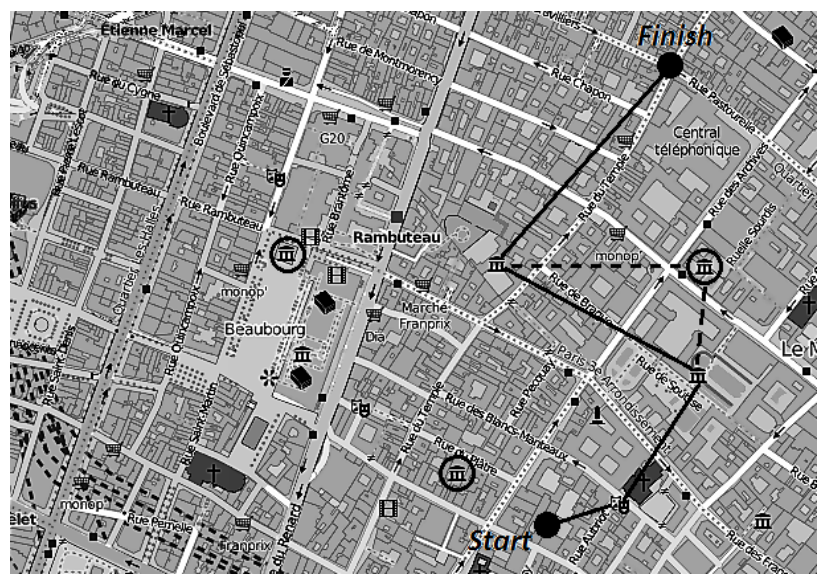

Fig. 4. One iteration of the route generation using GRASP

3) Ant Colony Optimization: The promising way is to use ant colony optimization (ACO) known since 1991 [21] and originally developed for solving a problem of finding an optimal path on a graph. A traditional ant colony algorithm is based on modeling the behavior of the ants dropping pheromones while deciding where to go depending on the intensiveness of pheromone trails. If an independent ant moves rather randomly, an ant discovering a previously laid pheromone trail follows this trail with higher probability. As a "side" effect, an ant following such previously laid trail reinforces the amount of pheromones on its way. There are ACO applications for many areas; in [22] there is a description of ACO application for a traveler salesman problem which is often a part of travel planning algorithms. An interesting ACO modification for tourist route planning was described in [23] as a formal foundation for a food tour recommendation system.

The solution can be enhanced by taking into consideration such important leisure walk properties as walk time, time required to visit a POI, nutrition conditions and other characteristics.

\section{A Prototype Software System}

In this section we describe the software components developed to demonstrate the key ideas of our approach, namely: making suggestions, interface simplification, implicit actions preferred, a focus on the above mentioned selected aspects. 


\section{A. Component for Interactive Itinerary Construction Inte- grated with OpenStreetMap}

According to an annotated travel itinerary concept presented in Section III-B, we developed an interface allowing to deal with a diversity of data to be visualized along the editable itinerary. Figure 5 shows a fragment of a POI description in terms of domain-specific ontology presented in Figure 1.

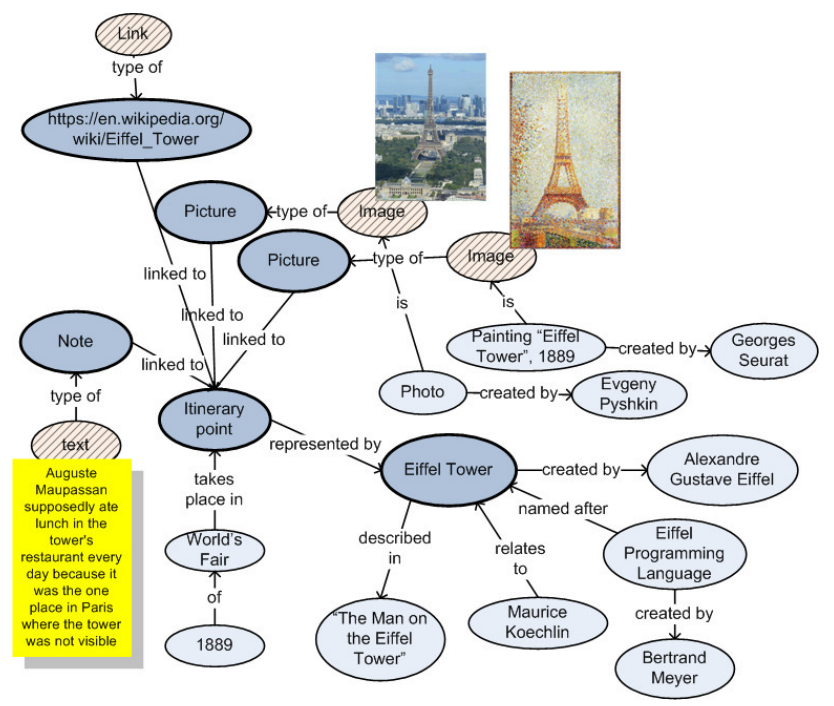

Fig. 5. A POI described in terms of domain-specific ontology (fragment)

Figure 6 shows a main panel of our prototype application for annotated itinerary construction together with some examples of POI annotations. As an electronic map service we use OpenStreetMap (OSM) ${ }^{23}$ which is a collaborative project for free editable world maps creation. In our implementation a JMapViewer component is used.

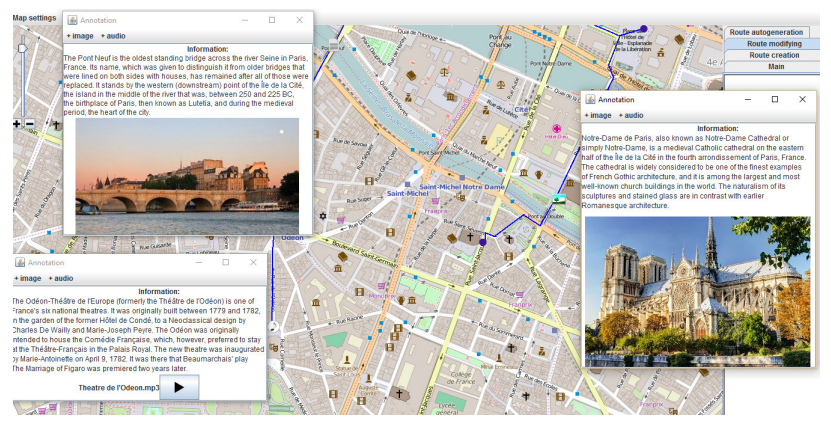

Fig. 6. Main frame window with an example of constructed itinerary

Users are able to select a search area on the map in order to allow suggesting the POIs for further consideration for including them to the itinerary. Figure 7 gives an idea of the adviser component user interface.

In sum, currently the system supports the following features:

\footnotetext{
${ }^{23} \mathrm{http}: / / w w w . o p e n s t r e e t m a p . o r g$
}

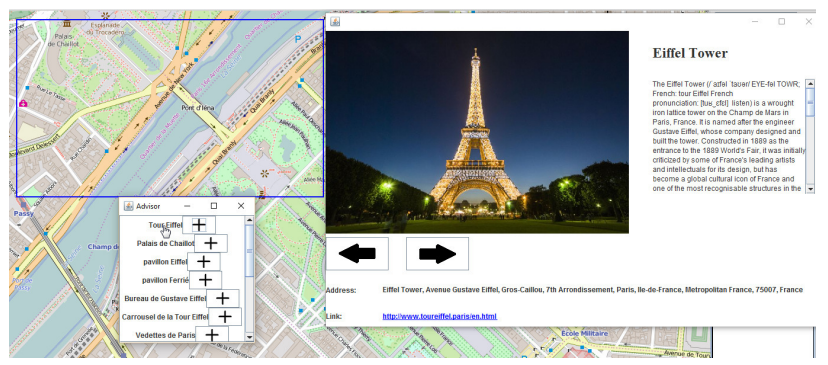

Fig. 7. Interactive adviser: attractions within the selected area

- Ability to create the route itself and to add the annotations containing text information, images, audio, links to web sites, etc.;

- Ability to modify the created tourist route;

- Ability to search POI-related information on the web;

- Automatic tourist route construction.

\section{B. Automatic Itinerary Construction}

For the leisure walk itinerary automation we use the following simplified scenario:

1) Define a time slot, select the departure and destination points. Define other constrains if required.

2) Explore potential locally accessible POIs for the current point on the route (initially the current point is set to the departure point).

3) Evaluate the POIs by using some formalized model for taking into account the degree of POI popularity, attractiveness, price to visit, location, etc.

4) Rank the POI and add the best ranked POIs to the part of the route in progress.

Steps 2-4 are repeated until the destination point is reached.

The standard task of tourist route generation is formalized by Souffriau [24] as follows:

Assume there are $N$ POIs. For every POI: $x_{i j}=1$, if there is a path between the POIs $i$ and $j$, otherwise $x_{i j}=0 . S_{i}$ is a $i$ th POI's score, $i$ ranging from 1 (departure) to $N$ (destination). Time $t_{i j}$ corresponds to the shortest path from point $i$ to point $j$. The total score $S_{\text {total }}$ has to be maximized within the limit $T_{\max }$ time.

This model sets boundaries of the future route and determines criteria for the best tourist route which is the best selection of the tourist objects and the best path connecting these objects.

Due to the fact that the POI score depends on its place along the route, each potentially accessible POI's score has to be recalculated at each iteration. In order to explore POIs locally we use the geometric model shown in Figure 8.

This geometric model has the following parameters: Start, Finish - the arrival and departure points within the route area, $a$ - the semi-major axis of the search area, $b$ - the semi-minor axis of the search area, $c$ - half of the focal distance of the search area, $S_{\max } / 2$ - half of the maximum distance that can be covered for the remaining time, $\alpha$ - search area angle of rotation, $\gamma-$ semi-minor axis minimization coefficient. 


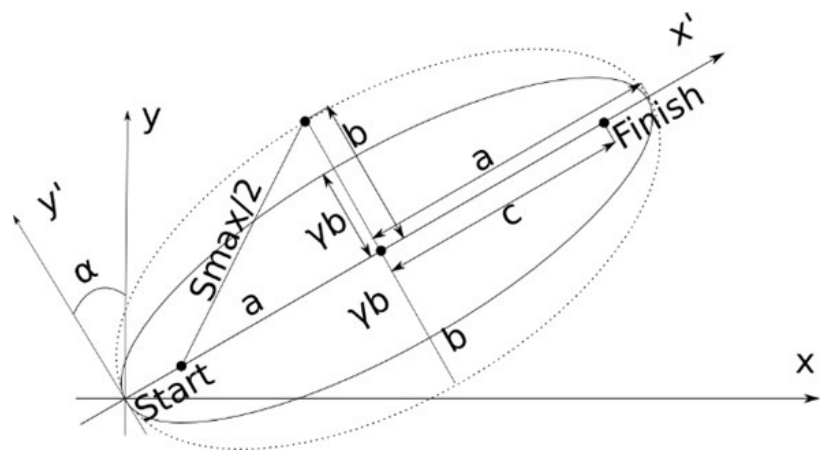

Fig. 8. Exploring local area

Unlike to the model used in the earlier mentioned Aurigo project, where the authors introduced a Pop Radius for exploring the POIs in the circled local area [10] (similar idea is also used in ATIPS project [25]), we use an elliptic model for the local POI exploration area. The elliptic form of the local region, where the potential POIs to visit are explored, allows us to use ellipse particularity: the sum of the distances to the two focal points is constant for every point on the curve. It means that if this sum is equal to the distance to the most distant point, a person can theoretically reach it within the given time and speed limits; each point outside the ellipse couldn't be reached. So, too distant POIs must be excluded from the short list used for further analysis. The POIs located close to the border of the ellipse may also be excluded from the search, otherwise it may happen that the resulting route is too sparse: a traveller will spend much time to walk in-between, instead of visiting the selected attractions.

In current implementation, we used an extension of a gradient descent algorithm for searching POIs to be included to the route. The extension is as follows: searching a new POI to be included occurs in the area with a maximum distance between two objects in the buffer route. This modification makes possible to reduce the maximum distance between the tourist objects and to exclude from the consideration hardly reachable objects. Then the selected objects are evaluated in order to find the object with the best score.

\section{Implementing A Simplified Scenario for Meetings Halfway}

Let us examine one interesting use case for suggestion oriented routing services which is a service targeting not the only user but the joint interests of several independent users.

Even in the case of a simplified scenario of arranging a meeting of two travelers, the task is not trivial: the involved persons have to consider air flight prices, flight schedule, tickets availability, accommodation and living costs. Huge arrays of data are potentially available via existing Internet services, but it is almost impossible to process them manually: an air ticket price and availability might change very quickly and dramatically in time, currency exchange rates are also not stable, there is a huge amount of data on flight connections, to cite a few.
We follow an idea similar to Google maps based Meetways application [26] developed since about 2008 [27]. One more example is Geo Meetpoint [28]. Probably the closest implementation is provided by Meet Me in the Middle application [29]. The latter has an easy-to-use interface and lightweight design fitting well searching for short distance routes, but there is limited support for cross-border points.

Informally, our model scenario could be described as a story of two friends trying to find a suitable meeting point:

Alex lives in St. Petersburg, Russia, while his girlfriend Tina lives in London, UK. They would like to meet each other. However, there are some constrains: they are students (so, they have rather limited funding), currently Alex has no UK visa (and it takes much time to get it), however they are open for any idea about the suitable place.

Saying more formally, assume City $y_{1}$ is a city where Alex flies from, and $\mathrm{City}_{2}$ is one where Tina flies from, while City $_{3}$ is a possible halfway meeting place. A set $R_{1}$ is a set of possible flights departing from the City $_{1}$ airports, while a set $R_{2}$ is a set of possible flight departing from City . Then an intersection $X$ of $R_{1}$ and $R_{2}$ provides the selection of flights which correspond to the possible meeting places. In order to find the best choice we have to download the detailed flight information (prices and available dates) for all the flights departing from the City $y_{1}$ and City $_{2}$ airports. Then we consider the combinations of all the destinations from the set $X$ corresponding to the flights departing from City $_{1}$ or $C i t y_{2}$. Such combinations give us an array of one-way flights. Then we add return flights in order to consider the full trip cost. Finally, the selection is sorted so as to discover the best options. Figure 9 illustrates the issue.

We organized the prototype implementation by introducing three components: web data access, data matching analysis and end user interface. First component is responsible for downloading data from available web sites providing access to flight data. Currently we use an aviasales.ru [30] open API allowing us to get flight information with dates, prices and possible directions from a selected city. Web data is parsed by a Python component. Data are extracted by using Requests library [31]; the response is received in JSON format [32]. Here is an example of such a response:

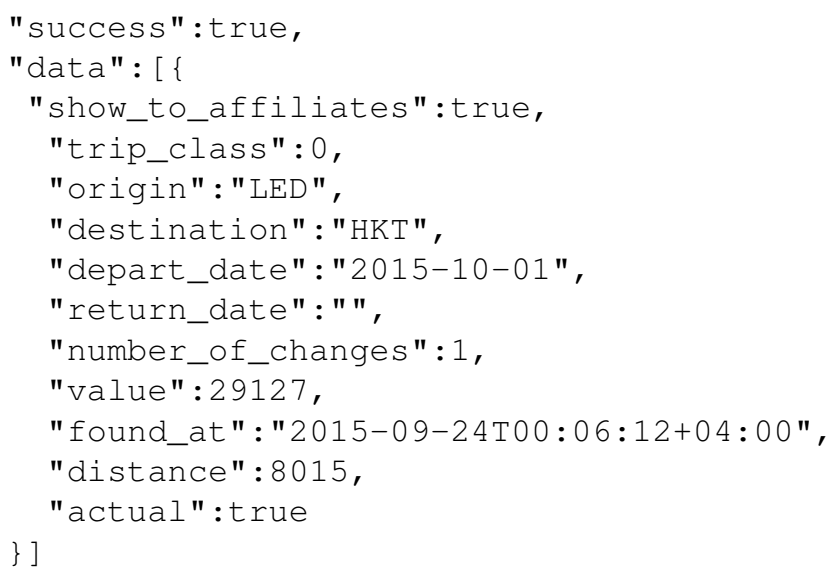


Figure 10 shows the user interface supporting four options: first departure city selection, second departure city selection, trip duration (in days) and desired departure date. Webapplication is implemented by using Flask [33].

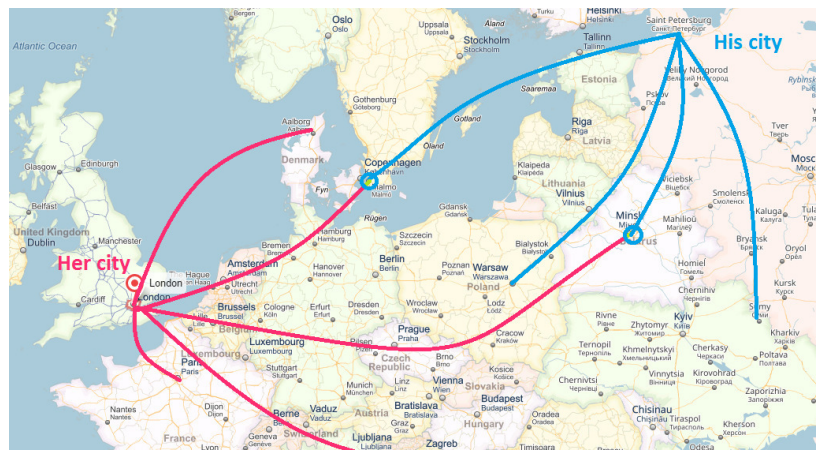

Fig. 9. A problem of finding a meeting point for two travelers

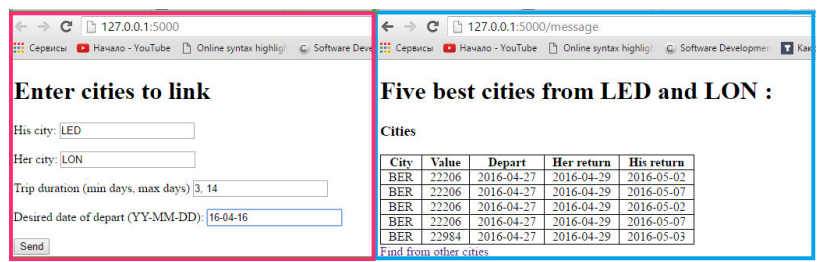

Fig. 10. A selection of flights which fit the user input

As a main result, currently the application yields a suggestion. Before any decision could be made, the application requires much more information than any user is able to handle. Thus, the implementation illustrates a concept of managed suggestion: we analyze plenty of flight related information and suggest the most suitable option. The solution can be extended so as to support many different use cases: meeting in a city, going to a cinema, following a music band in a tour, finding a place for a conference, arranging a business meeting, and many others.

\section{Conclusion}

In this paper we made an effort to touch a selection of aspects of today's information systems for travelers where there is a convergence of approaches being developed within the framework of human-centric, aware and urban computing. We designed the software components targeting better travel personalization and user collaboration with special emphasis on suggesting better itineraries both in local and global scope. Specifically, the following ongoing projects were presented:

- A visual OpenStreeMap based tool for constructing annotated travel itineraries: the tool is useful both for independent travelers and for guides preparing the journey for their clients;

- A tool for automatic of travel itinerary construction integrated with the above mentioned visual guide assistant;
- A Meeting Point application suggesting a suitable halfway meeting point for two travelers using air flights for reaching the meeting destination.

We believe that currently the process leading us towards better route and leisure suggestions is being rethought with more attention to the following aspects:

- More orientation on planning by collaboration;

- Deeper integration with external services including electronic maps, navigation systems, knowledge resources, libraries, etc.;

- Resolving usability issues and developing better intelligent user interfaces and HCI solutions for leveraging user experience and taking into account existing features of present day computers and portable smart devices;

- Planning experiments conducted by real users.

With regard to the content related improvements, we believe that automatic tourist route generation algorithms have to be extended in order to support an extremely useful feature like constructing the thematically linked and multi-day journeys. We think about deeper integration with multimedia features used during the suggested sightseeing walks. We also consider investigating the issue of using old maps available as images. A perspective to the ancient views accessible electronically will significantly extend the way to learn history while visiting tourist attractions all around the world.

\section{APPENDIX}

In research works it is rarely shown how information about existing relevant domain-specific solutions are being retrieved. Table I and Table II give a hint how the searching process was organized in our case. We included information about search queries, extended queries and a selection of Google results obtained while using Google Chrome in private view mode so as not to keep any search history information. Results mentioned as "Direct" mean that they are obtained directly as Google web search output. Results discovered after subsequent examination of "direct" resources are mentioned as "Indirect". We also noted the results relevance to the scope of current contribution. Some of explored models, approaches and algorithms provide good foundation for further investigations within the framework of our research.

\section{ACKNOWLEDGMENT}

The authors thank Matvei Pyshkin for his valuable contribution to the detailed survey of the solutions, products and services examined in our work.

\section{REFERENCES}

[1] M. Andreea et al., "The emerging technological trends in the tourism industry," Annals-Economy Series, pp. 73-76, 2014.

[2] Y. Zheng, L. Capra, O. Wolfson, and H. Yang, "Urban computing: concepts, methodologies, and applications," ACM Transactions on Intelligent Systems and Technology (TIST), vol. 5, no. 3, p. 38, 2014.

[3] R. F. Joseph and A. A. Godbole, "An intelligent traveling companion for visually impaired pedestrian," in Circuits, Systems, Communication and Information Technology Applications (CSCITA), 2014 International Conference on, April 2014, pp. 283-288. 
[4] V. Mladenovic, M. Lutovac, and M. Lutovac, "Electronic tour guide for android mobile platform with multimedia travel book," in Telecommunications Forum (TELFOR), 2012 20th, Nov 2012, pp. 1460-1463.

[5] R. Karimi, A. Nanopoulos, and L. Schmidt-Thieme, "Rfid-enhanced museum for interactive experience," in Multimedia for cultural heritage. Springer, 2012, pp. 192-205.

[6] J.-P. Gerval and Y. Le Ru, "Fusion of multimedia and mobile technology in audioguides for museums and exhibitions: from bluetooth push to web pull," 2011.

[7] Y.-M. Huang, C.-H. Liu, C.-Y. Lee, Y.-M. Huang et al., "Designing a personalized guide recommendation system to mitigate information overload in museum learning."

[8] T. Y. Lim, "Designing the next generation of mobile tourism application based on situation awareness," in Network of Ergonomics Societies Conference (SEANES), 2012 Southeast Asian. IEEE, 2012, pp. 1-7.

[9] T.-D. Cao and N.-D. Tuan, "Improving travel information access with semantic search application on mobile environment," in Proceedings of the 9th International Conference on Advances in Mobile Computing and Multimedia, ser. MoMM '11. New York, NY, USA: ACM, 2011, pp. 95-102. [Online]. Available: http://doi.acm.org/10.1145/2095697. 2095716

[10] A. Yahi, A. Chassang, L. Raynaud, H. Duthil, and D. H. P. Chau, "Aurigo: an interactive tour planner for personalized itineraries," in Proceedings of the 20th International Conference on Intelligent User Interfaces. ACM, 2015, pp. 275-285.

[11] V. W. S. Tung and J. B. Ritchie, "Exploring the essence of memorable tourism experiences," Annals of Tourism Research, vol. 38, no. 4, pp. 1367-1386, 2011.

[12] A. Smirnov, A. Kashevnik, N. Shilov, N. Teslya, and A. Shabaev, "Mobile application for guiding tourist activities: tourist assistant-tais," in Open Innovations Association (FRUCT16), 2014 16th Conference of IEEE, 2014, pp. 95-100.

[13] I. Brilhante, J. A. Macedo, F. M. Nardini, R. Perego, and C. Renso, Advances in Information Retrieval: 36th European Conference on IR Research, ECIR 2014, Amsterdam, The Netherlands, April 13-16, 2014. Proceedings. Cham: Springer International Publishing, 2014, ch. TripBuilder: A Tool for Recommending Sightseeing Tours, pp. 771-774. [Online]. Available: http://dx.doi.org/10.1007/978-3-319-06028-6 93

[14] _ "Scaling up the mining of semantically-enriched trajectories: Tripbuilder at the world level," 2015, accessed on April 23, 2016. [Online]. Available: http://ceur-ws.org/Vol-1404/paper_12.pdf

[15] B. Skripal and E. Pyshkin, "Automated leisure walk route generation for an interactive travel planner," in Proceedings of the International Workshop on Applications in Information Technology (IWAIT-2015), The University of Aizu. The University of Aizu Press, Oct 2015, pp. 29-32.

[16] A. Baratynskiy and E. Pyshkin, "Traveler guide assistant: Introducing an application for an openstreetmap based travel itinerary construction," in Proceedings of the International Workshop on Applications in Information Technology (IWAIT-2015), The University of Aizu. The University of Aizu Press, Oct 2015, pp. 25-28.

[17] G. Chen, S. Wu, J. Zhou, and A. K. Tung, "Automatic itinerary planning for traveling services," Knowledge and Data Engineering, IEEE Transactions on, vol. 26, no. 3, pp. 514-527, 2014.

[18] A. Garcia, O. Arbelaitz, M. T. Linaza, P. Vansteenwegen, and W. Souffriau, Personalized tourist route generation. Springer, 2010.

[19] S. Yu, J. Zhao, and C. Hu, "Route planning of stacker by improved genetic algorithm," Automatic Control and Artificial Intelligence (ACAI 2012), International Conference on, 2012.

[20] Z. Zabinsky, "Random search algorithms," Department of Industrial and Systems Engineering, University of Washington, USA, 2009.

[21] A. Colorni, M. Dorigo, V. Maniezzo et al., "Distributed optimization by ant colonies," in Proceedings of the first European conference on artificial life, vol. 142. Paris, France, 1991, pp. 134-142.

[22] T. Stützle and M. Dorigo, "Aco algorithms for the traveling salesman problem," Evolutionary Algorithms in Engineering and Computer Science, pp. 163-183, 1999.

[23] K. Sriphaew and K. Sombatsricharoen, "Food tour recommendation using modified ant colony algorithm," 5th International Conference on Computing and Informatics, ICOCI 2015 11-13 August, 2015 Istanbul, Turkey, 2015.

[24] W. Souffriau, Automated Tourist Decision Support. Katholieke Universiteit Leuven, 2010.

[25] H.-T. Chang, Y.-M. Chang, and M.-T. Tsai, "Atips: Automatic travel itinerary planning system for domestic areas," Computational Intelligence and Neuroscience, vol. 2016, 2015

[26] "Meetways: Meet me in the middle" accessed: Dec 30, 2015. [Online]. Available: http://content.usatoday.com/communities/popcandy/ post/2008/10/780903/1\#.Voj79U_6LGA

[27] W. Matheson, "Why go the distance when you can go half?" Oct 2008, accessed: Mar 10, 2016. [Online]. Available: http: //smallbusiness.chron.com/arrange-business-meeting-75187.html

[28] "Geo meetpoint," accessed: Mar 10, 2016. [Online]. Available: http://www.geomidpoint.com/meet/

[29] "Meet me in the middle," accessed: Mar 11, 2016. [Online]. Available: https://itunes.apple.com/us/app/meet-me-in-the-middle/ id826982528? $\mathrm{mt}=8$

[30] “Aviasales api," accessed: Dec 29, 2016. [Online]. Available: https://www.aviasales.ru/API

[31] "Requests: Http for humans," accessed: Mar 15, 2016. [Online]. Available: http://docs.python-requests.org/en/master/

[32] “18.2.json encoder and decoder," accessed: Mar 15, 2016. [Online] Available: https://docs.python.org/2/library/json.html

[33] "Flask web development, one drop at a time," accessed: Apr 28, 2016 [Online]. Available: http://flask.pocoo.org/

[34] A. Rikitianskii, M. Harvey, and F. Crestani, Advances in Information Retrieval: 36th European Conference on IR Research, ECIR 2014, Amsterdam, The Netherlands, April 13-16, 2014. Proceedings. Cham: Springer International Publishing, 2014, ch. A Personalised Recommendation System for Context-Aware Suggestions, pp. 63-74. [Online]. Available: http://dx.doi.org/10.1007/978-3-319-06028-6_6

[35] J. Duffy, "The best travel apps of 2015," PC, August 2015.

[36] R. Anacleto, L. Figueiredo, A. Almeida, and P. Novais, "Mobile application to provide personalized sightseeing tours," Journal of Network and Computer Applications, vol. 41, pp. 56 - 64, 2014. [Online]. Available: http://www.sciencedirect.com/science/article/ pii/S1084804513002105

[37] M. De Choudhury, M. Feldman, S. Amer-Yahia, N. Golbandi, R. Lempel, and C. Yu, "Automatic construction of travel itineraries using social breadcrumbs," in Proceedings of the 21st ACM conference on Hypertext and hypermedia. ACM, 2010, pp. 35-44.

[38] R. Rajeswari and J. M. Mannan, "Efficient multiuser itinerary planning for travelling services using fkm-clustering algorithm," 2015.

[39] D. Batchelor, "Collaborative travel and tourism: the best way to predict the future is to invent it," January 2012, accessed: Apr 23, 2016. [Online]. Available: http://blogamadeus.com/18/01/ collaborative-travel-the-best-way-to-predict-the-future-is-to-invent-it/

[40] A. Henri, "Five best travel planning apps," November 2013 , accessed: Apr 23, 2016. [Online]. Available: http://lifehacker.com/ five-best-travel-planning-apps- 1470002139

[41] S. Dunstall, M. E. Horn, P. Kilby, M. Krishnamoorthy, B. Owens, D. Sier, and S. Thiebaux, "An automated itinerary planning system for holiday travel," Information Technology \& Tourism, vol. 6, no. 3, pp. 195-210, 2003

[42] S. B. Roy, G. Das, S. Amer-Yahia, and C. Yu, "Interactive itinerary planning," in Data Engineering (ICDE), 2011 IEEE 27th International Conference on. IEEE, 2011, pp. 15-26.

[43] A. Gionis, T. Lappas, K. Pelechrinis, and E. Terzi, "Customized tour recommendations in urban areas," in Proceedings of the 7th ACM international conference on Web search and data mining. ACM, 2014 pp. 313-322.

[44] X. Li, "Multi-day and multi-stay travel planning using geo-tagged photos," in Proceedings of the Second ACM SIGSPATIAL International Workshop on Crowdsourced and Volunteered Geographic Information. ACM, 2013, pp. 1-8.

[45] A. Majid, L. Chen, H. T. Mirza, I. Hussain, and G. Chen, "A system for mining interesting tourist locations and travel sequences from public geo-tagged photos," Data \& Knowledge Engineering, vol. 95, pp. 66-86, 2015

[46] L.-Y. Wei, Y. Zheng, and W.-C. Peng, "Constructing popular routes from uncertain trajectories," in Proceedings of the 18th ACM SIGKDD international conference on Knowledge discovery and data mining. ACM, 2012, pp. 195-203. 
TABLE I

QUERIES AND RESULTS (PART 1)

\begin{tabular}{|c|c|c|c|c|}
\hline \multirow{2}{*}{ Query } & \multicolumn{4}{|l|}{ Finding } \\
\hline & Link & Description & $\begin{array}{l}\text { Direct } \\
\text { or } \\
\text { Indirect }\end{array}$ & Relevance \\
\hline \multirow[t]{5}{*}{ sightseeing tools } & http://link.springer.com/chapter/10.1007/978-3-319-06028-6_93 & $\begin{array}{l}\text { "TripBuilder: A Tool for } \\
\text { Recommending Sightsee- } \\
\text { ing Tools" (Article, 2014) } \\
{[13]}\end{array}$ & Direct & Yes \\
\hline & http://ceur-ws.org/Vol-1404/paper_12.pdf & $\begin{array}{l}\text { "Scaling up the Mining } \\
\text { of Semantically-enriched } \\
\text { Trajectories: TripBuilder } \\
\text { at the World Level" (Ar- } \\
\text { ticle, 2015) [14] }\end{array}$ & Indirect & Yes \\
\hline & http://link.springer.com/chapter/10.1007/978-3-319-06028-6_6 & $\begin{array}{l}\text { "A Personalised } \\
\text { Recommendation System } \\
\text { for Context-Aware } \\
\text { Suggestions" } \quad \text { (Article, } \\
\text { 2014) [34] }\end{array}$ & Indirect & Yes \\
\hline & https://www.londontoolkit.com/mnu/london_tours.htm & Travel company web site & Direct & No \\
\hline & http://googlesightseeing.com/tools/ & $\begin{array}{l}\text { Virtual tours (not affiliated } \\
\text { with Google) }\end{array}$ & Direct & No \\
\hline \multirow{6}{*}{ sightseeing applications } & http://www.tripomatic.com & $\begin{array}{l}\text { Tripomatic Trip Planner } \\
\text { and Sightseeing Travel } \\
\text { Guide with Offline Maps }\end{array}$ & Direct & Yes \\
\hline & https://itunes.apple.com/us/app/id554726752?mt=8 & $\begin{array}{l}\text { izi.TRAVEL - sightseeing, } \\
\text { museum and landmark au- } \\
\text { dio tour guide app for } \\
\text { travelers }\end{array}$ & Direct & Yes \\
\hline & http://www.pcmag.com/article2/0,2817,2422244,00.asp & $\begin{array}{l}\text { "The Best Travel Apps of } \\
\text { 2015" (PC News, Article, } \\
\text { 2015) [35] }\end{array}$ & Direct & Yes \\
\hline & http://www.sciencedirect.com/science/article/pii/S1084804513002105 & $\begin{array}{l}\text { Mobile application to } \\
\text { provide personalized } \\
\text { sightseeing tours (Article, } \\
\text { 2014) [36] }\end{array}$ & Direct & Yes \\
\hline & http://www.tourpal.com/ & City audio guides & Direct & Partially \\
\hline & https://play.google.com/store/apps/details?id=com.touristeye & $\begin{array}{l}\text { Tourist Eye App form } \\
\text { Lonely Planet }\end{array}$ & Direct & Partially \\
\hline \multirow{4}{*}{ visual travel guide } & http://www.visualtravelguide.com/ & Photo collection & Direct & No \\
\hline & http://www.dk.com/us/travel/ & $\begin{array}{l}\text { DK publishing travel } \\
\text { guides }\end{array}$ & Direct & No \\
\hline & https://www.virtualtourist.com/ & Telling stories forum & Direct & No \\
\hline & https://www.explorra.com/labs/travel-by-color & $\begin{array}{l}\text { Discover travel destina- } \\
\text { tions by color }\end{array}$ & Direct & Partially \\
\hline \multirow[t]{3}{*}{ travel itinerary construction } & http://www.openu.ac.il/personal_sites/moran-feldman/ & $\begin{array}{l}\text { "Automatic Construction } \\
\text { of Travel Itineraries using } \\
\text { Social Breadcrumbs" (Ar- } \\
\text { ticle, 2010) [37] }\end{array}$ & Direct & Yes \\
\hline & https://www.irjet.net/archives/V2/i2/Irjet-v2i221.pdf & $\begin{array}{lr}\text { "Efficient } & \text { Multiuser } \\
\text { Itinerary Planning for } \\
\text { Travelling } & \text { Services } \\
\text { Using FKM-Clustering } \\
\text { Algorithm" } \\
2015)[38]\end{array}$ & Direct & Yes \\
\hline & http://kspt.ftk.spbstu.ru/media/files/2015/iwait-2015/proceedings/4.pdf & $\begin{array}{lr}\text { "Traveler } & \text { Guide } \\
\text { Assistant: Introducing } \\
\text { an Application for } \\
\text { an OpenStreetMap } \\
\text { Based Travel Itinerary } \\
\text { Construction" } \\
\text { previous paper) }[16]\end{array}$ & Direct & Yes \\
\hline \multirow[t]{2}{*}{ travel diary } & www.traveldiariesapp.com/ & $\begin{array}{l}\text { Creating user travel di- } \\
\text { aries (pictures, texts, sim- } \\
\text { ple maps) }\end{array}$ & Direct & Partially \\
\hline & https://play.google.com/store/apps/details?id=ch.robera.android.traveldiary & $\begin{array}{l}\text { Travel diary app for An- } \\
\text { droid }\end{array}$ & Direct & Partially \\
\hline \multirow{2}{*}{ travel planning } & https://www.triphobo.com/ & Trip time scheduler & Direct & Yes \\
\hline & https://www.tripit.com/ & Travel scheduler & Direct & Partially \\
\hline
\end{tabular}


TABLE II

QUERIES AND RESUlTS (PART 2)

\begin{tabular}{|c|c|c|c|c|}
\hline \multirow{2}{*}{ Query } & \multicolumn{4}{|l|}{ Finding } \\
\hline & Link & Description & $\begin{array}{l}\text { Direct } \\
\text { or } \\
\text { Indirect }\end{array}$ & Relevance \\
\hline \multirow[t]{2}{*}{ collaborative traveling } & http://www.collaborativeconsumption.com/2014/06/25/ & $\begin{array}{l}\text { "Collaborative Economy } \\
\text { Services: Changing the } \\
\text { Way We Travel" (Internet } \\
\text { article on economics and } \\
\text { organization, not technol- } \\
\text { ogy related) }\end{array}$ & Direct & No \\
\hline & http://blogamadeus.com/18/01/ & $\begin{array}{l}\text { "Collaborative travel and } \\
\text { tourism: the best way to } \\
\text { predict the future is to } \\
\text { invent it" (Blog article, } \\
\text { 2012) [39] }\end{array}$ & Direct & Yes \\
\hline \multirow[t]{4}{*}{ collaborative traveling tools } & https://travefy.com/ & $\begin{array}{l}\text { Product for travel agents } \\
\text { and for travelers for } \\
\text { planning collaborative } \\
\text { itineraries }\end{array}$ & Direct & Partially \\
\hline & http://toomanyadapters.com/7-collaboration-tools-travelling-entrepreneurs/ & $\begin{array}{l}\text { Entrepreneurship related } \\
\text { article }\end{array}$ & Direct & No \\
\hline & http://lifehacker.com/five-best-travel-planning-apps-1470002139 & $\begin{array}{l}\text { Internet review on travel } \\
\text { planning [40] }\end{array}$ & Direct & Yes \\
\hline & https://www.planapple.com/ & $\begin{array}{l}\text { Simple application for } \\
\text { travel planning }\end{array}$ & Direct & Partially \\
\hline \multirow[t]{3}{*}{ travel tracking } & https://www.tripit.com/destinations/the-ultimate-travel-tracker/ & $\begin{array}{lcr}\begin{array}{l}\text { Distance } \\
\text { mileage }\end{array} & \text { tracking } & \text { and } \\
\text { calculation } & & \text { time } \\
\text { calcula } & & \\
\end{array}$ & Direct & No \\
\hline & http://www.trip-journal.com/ & $\begin{array}{l}\text { Mobile app for trip track- } \\
\text { ing, recording, document- } \\
\text { ing and sharing }\end{array}$ & Direct & Yes \\
\hline & https://trackmytour.com/ & $\begin{array}{l}\text { Mobile app for creating } \\
\text { online maps of your jour- } \\
\text { ney for friends and family } \\
\text { to follow along }\end{array}$ & Direct & Yes \\
\hline \multirow{9}{*}{ travel itinerary automation } & http://triplantica.com/ru & $\begin{array}{l}\text { Visual travel scheduler } \\
\text { with e-map integration }\end{array}$ & Direct & Yes \\
\hline & https://www.researchgate.net/publication/220542946 & $\begin{array}{l}\text { "An Automated Itinerary } \\
\text { Planning System for } \\
\text { Holiday Travel" (Article, } \\
\text { 2003) [41] }\end{array}$ & Direct & Yes \\
\hline & http://www.computer.org/csdl/trans/tk/2014/03/ttk2014030514-abs.html & $\begin{array}{l}\text { "Automatic Itinerary Plan- } \\
\text { ning for Traveling Ser- } \\
\text { vices" (Article, 2014) [17] }\end{array}$ & Direct & Yes \\
\hline & http://ieeexplore.ieee.org/xpl/articleDetails.jsp?arnumber=5767920 & $\begin{array}{l}\text { "Interactive Itinerary } \\
\text { Planning" (Article, 2011) } \\
\text { [42] }\end{array}$ & Indirect & Yes \\
\hline & http://dl.acm.org/citation.cfm?id=2559893 & $\begin{array}{l}\text { "Customized tour recom- } \\
\text { mendations in urban ar- } \\
\text { eas" (Article, 2014) [43] }\end{array}$ & Indirect & Yes \\
\hline & http://dl.acm.org/citation.cfm?id=2534733 & $\begin{array}{l}\text { "Multi-day and multi-stay } \\
\text { travel planning using geo- } \\
\text { tagged photos" (Article, } \\
\text { 2013) [44] }\end{array}$ & Indirect & Yes \\
\hline & http://www.sciencedirect.com/science/article/pii/S0169023X14000962 & $\begin{array}{l}\text { "A system for mining in- } \\
\text { teresting tourist locations } \\
\text { and travel sequences from } \\
\text { public geo-tagged photos" } \\
\text { (Article, 2014) [45] }\end{array}$ & Indirect & Yes \\
\hline & http://dl.acm.org/citation.cfm?id=2339562 & $\begin{array}{lr}\text { "Constructing } & \text { popular } \\
\text { routes from } & \begin{array}{r}\text { uncertain } \\
\text { trajectories" }\end{array} \\
\text { (Article, }\end{array}$ & Indirect & Yes \\
\hline & http://kspt.ftk.spbstu.ru/media/files/2015/iwait-2015/proceedings/5.pdf & $\begin{array}{l}\text { "Automated leisure walk } \\
\text { route generation for an } \\
\text { interactive travel planner" } \\
\text { (Our previous paper) [15] }\end{array}$ & Direct & Yes \\
\hline
\end{tabular}

